\title{
Green Synthesis of Nanoparticles and their Possible Avenues in Environmental Application - A Review
}

\author{
S. Saritha ${ }^{1}$ and V. Prabha ${ }^{2} *$ \\ ${ }^{1}$ MMES Women's Arts and Science College, Vellore, Tamil Nadu, India \\ ${ }^{2}$ Department of Biochemistry, DKM College for Women, Vellore, Tamil Nadu, India \\ *Corresponding author
}

\section{A B S T R A C T}

\section{Keywords}

Nanoremediation,

Nanotechnology,

Green synthesis,

Photocatalysis,

Electro signaling

Article Info

Accepted:

15 September 2019

Available Online:

10 October 2019
Nanotechnology plays a crucial role in addressing the innovations and solution to vast challenges in various fields. In recent years, green synthesis has gained extensive attention based on its reliability and stability. The use and development of nanomaterials using biogenic approach has several advantaged on environment and defined as nanoremediation. This beneficial technology can also be designed in order to decrease the risk of environmental pollution. This review deals with the types of nanoparticles, various routes involved in the synthesis of the nanomaterial. This mini review highlights the employment of green synthesized nanomaterials in gas sensors, electro signaling and photocatalysis.

\section{Introduction}

Nanotechnology has emerged during 1980's and has become the center of attraction in the $21^{\text {st }}$ century for both public and scientific community. Nanotechnology can be simply defined as understanding and control of matter at dimension between 1 and $100 \mathrm{~nm}$ that results in succeeding novel and effective applications (Murugan et al 2014). In other words, engineering and exploring the applications of nanomaterials with smaller size(Whatmore 2006). These particles are microscopic with minimum one dimension less than $100 \mathrm{~nm}(\mathrm{Garg}$ et al 2011). The physical properties of nanoparticles differ largely compared with bulk materials because nanoparticle exhibit relatively large surface area. Additionally, the particle at nanoscale has length lesser than de Broglie wavelength of the charge carrier or wavelength of light. This interesting property of nanoparticle has made them an efficient candidate in various fields of science and technology. This modern day technology plays a vital role in day to day life of modern human being.

In this modern era, nanotechnology has attained greater importance and its budding applications has several beneficial impacts on 
the society in various fields such as Environment, Engineering, Pharmaceutical, Agriculture and so on. Among various general applications, use of Titanium (Ti) and Zinc (Zn) in bioremediation has highly attracted the scientific community. The involvement of nanotechnology in environmental sector widely includes waste water treatment, soil remediation, sensors and energy storages etc (Wang and Dai 2013). On the other hand, scheming the nanomaterial for environmental issues should also bear safety towards the ecosystem which greatly includes living beings and the sources of life with potential environmental benefits(Hutchison 2008). In this mini review, we have discussed about the types of platform of nanoparticles, general approaches to synthesize nanoparticles by biological means and its use in environmental applications.

\section{Numerous forms/platforms of nanoparticles}

The various forms of nanoparticles includes inorganic nanoparticles, polymeric nanoparticles, solid lipid nanoparticles, liposomes, nanocrystals, nanotubes, dendrimers etc (Fig 1). Inorganic nanoparticles have greatly attained the attention of the research community in the field of biotechnology mainly due to the exceptional physical property. These nanoparticle exhibit size dependent optical, magnetic, electronic and property of catalyzing the reaction (Ladj et al 2013).Polymeric nanoparticles are one such nanoparticles highly employed in research. The scattering of polymer and polymerization of monomers are the crucial approaches involved for the materialization of polymeric nanoparticles (Prasad Rao and Kurt Geckeler 2011). In conserving the liberating effectiveness of drug in 1990 solid lipid nanoparticles were introduced and they played a vital role in the field of drug delivery. They act as carrier system to emulsion, liposomes and polymeric nanoparticles (Abhilash 2010).
Liposomes are another form of nanoparticles used in the field of drug delivery that consist of one or more phospholipids bilayer that carry the compound of interest to the site of action. Liposomes are widely used in the field of pharmaceuticals and food industries in delivering the drug by acting as catalyst. Encapsulation of unstable compounds are done using the liposomes(Akbarzadeh et al 2013). Apart for these, quantum dots are semiconductors with size lesser than $10 \mathrm{~nm}$ in diameter. These quantum dots exhibit specific size dependent electronic and optical properties(Collier et al 1998). Most of the quantum dots are arranged based on core and shell material. The core consists of cadmium selenium as core and zinc selenium as cap or shell (Jovin 2003). These quantum dots are widely used in biological research such as fluorescence imaging and biomolecule tracking.

\section{Various routes for synthesis of nanoparticles}

Nanoparticles were synthesized by means of three different methods i) Chemical method ii) physical methods and iii) Biological method. Synthesis of nanoparticles by chemical means was considered to be quick and ancient methods but later it was found to be toxic due to the chemicals used during capping and stabilizing. These nanoparticles were observed to be toxic to ecosystem. On the other hand, physical method of nanoparticle synthesis is considered to one of the expensive methods involving complex means in fabricating the nanoparticles. Due to toxic effect, nanoparticle synthesized using physical and chemical methods are not employed in the field of drugs and therapeutics. To overcome these disadvantages, green synthesis of nanoparticles was introduced which results in non-toxic and eco-friendly compounds. It was observed that, the biological materials bear the tendency to reduce the metals to metal ions 
easily with less cost and low toxicity when compared with physical and chemical methods. For synthesizing metal or metal oxide nanoparticle, plant and microbial diversity has been highly exploited due to the presence of secondary metabolites such as flavones, terpenoids, carboxylic acids, phenols, aldehydes and ketones. These secondary metabolites play an essential in reducing metals into metal ions (Doble and Kruthiventi 2007).

\section{Green synthesis of nanoparticles}

Due to increased cost, high toxicity, higher radiation over environment and human beings, physical and chemical methods of nanoparticle fabrication is being less used. On the other hand, green synthesis of nanoparticles was found to be a single step process that utilize very less energy for initiating the reaction. This method of nanoparticle synthesis were considered to be an effective, non-toxic, bio friendly method (Dahoumane et al 2016; El-Rafie et al 2013; Husen and Siddiqi 2014; Khan et al 2015). Among plants and other biological components, bacteria play a key role in bioreduction of metal salts into metal ions. Generally, bacterial species are highly recommended in biotechnological applications such as genetic engineering, bioremediation, bioleaching etc(Gericke and Pinches 2006). Bacterial means of synthesis is found to be easier since the manipulation, growth and cultivation process is found to be simpler (Thakkar et al 2010). Likewise, fungi have many advantages over the other due to the existence of all indispensable metabolites on the surface of the cell wall (Narayanan and Sakthivel 2011). Comparatively, fungal isolates were observed to synthesis enormous quantity of nanoparticles when likened with that of bacteria (Mohanpuria et al 2008). Plants have higher potential in synthesizing nanoparticles efficiently and effectively with low cost. Various plants such as copper leaf, china rose, green tea, aloe vera, crown flower, alfalfa, mustard were highly studied for its efficacy in synthesizing nanoparticles in vivo by reducing metal salts to metal ions. The nanoparticles synthesized by means of green synthesis were found to be stable. $\mathrm{Ag}$ nanoparticles fabricated using tea leaf extract were found to be very stable when introduced into the aquatic environment(Sun et al 2014).

\section{Environmental nanotechnology \\ application of}

Environmental pollution and protection remains as an important issue to be addressed at the earliest for maintaining the healthy ecosystem. Trace amount of pest, oil, dye, heavy metals with high chloride concentration in water purifiers were reported by (Jadhav et al 2013). In order to remediate the pollution, various approaches has been employed which broadly includes, bioremediation, phytoremediation, rhizoremediation, nanotechnology etc. Recent studies utilize the efficiency of nanoparticles in remediating the polluted sites, which has now been termed as nano remediation. Nano remediation has become an effective method for remediating the polluted landfills using the substantial role in sensing, observing and remediating (Rajan 2011). These nano remediation remains as an alternate for the current day expensive treatments such as thermal treatment, chemical oxidation and surfactant co solvents flushing etc (Löffler and Edwards 2006).

Nanotechnology has been exploited in constructing low cost but highly sensitized detecting system for checking the quality of air and water with high stability and selectivity. These nanoparticles based detection system has the potential to detect toxins, heavy metals and other gaseous pollutants surrounded in the environment (Hristozov and Ertel 2009). These Nano 
sensors in an advanced level are being used to detect the presence of microbes in food and other edible substances (Butnar and Llop).

\section{Sensing and monitoring system}

\section{Gas sensors}

Gas sensors or chemical sensors play a crucial role in observing environmental pollution in air, water and soil (Zhang et al 2016). It is also employed in detecting the other environmental pollutions caused by organic dyes in food and leather industries. Specific and selective sensors are used for detecting the leakage of the toxic compound form the industries(Asad and Sheikhi 2016). Recently, sensors made up of nanoparticles such as $\mathrm{SnO}_{2}, \mathrm{WO}_{3}, \mathrm{ZnO}$ are recommended for gas sensors (Comini 2006 andKumar et al 2015). Due to the specific properties such as sensitivity, stability and low cost $\mathrm{ZnO}$ nanoparticles are used in determining the toxic compounds present in the environment (Han et al 2016 and Ozgur et al 2005).

\section{Electro chemical signaling}

Apart from heavy metal detection, single walled nanotubes were also used to develop a paper based sensor for detecting microcystin LR with detection limit of $0.6 \mathrm{ppb}$ (Wang et al 2009). Correspondingly, electrochemical immune sensor a single walled carbon nanohorns functionalized using analyte with detection limit of $0.03 \mu \mathrm{g} / \mathrm{ml}$ were designed (Zhang et al 2010). Similarly encapsulated Au nanoparticles were used for detecting the presence of pathogenic strain such as E. coli, Cryptosporidium $s p$ and Giardia sp etc. Toxins such as shiga-like toxin 1, cholera toxin, staphylococcal enterotoxin B were determined. Silver nanoparticles synthesized using Anacardium occidentale has been reported to be an effective probe in sensing chromium ions present in the tap water
(Balavigneswaran et al 2014).

Photocatalysis and catalytic efficacy of nanoparticles

Nanoparticle containing higher surface area are referred to possess higher catalytic activity. Several reactions such as reduction of nickel oxide to nickel (metal) are carried out by nanoparticles. Titanium dioxide has attracted the interest of the research community due to its uniqueness in photoreducing inorganic contaminants and inactivating microorganisms, and enhancing the photodegradation of numerous organic pollutants (Chong et al 2010; Kurniawan and Sillanpaa 2011). Since titanium exhibits less toxicity, high photoconductivity and stability it is been highly recommended for photodegradation study (Choi et al 2014). Development of photocatalytic process of non-metal doped $\mathrm{TiO}_{2}$ has exhibited enormous ability in treating water and considered to be more ecofriendly approach compared with the metal doped process in which the later process is vulnerable to corrosion and other metal problems. Apart from being an efficient candidate in photocatalysis, nanoparticles remain as a better catalyzer in enhancing the rate of reactions. Green synthesized $\mathrm{Ag}$ nanoparticles were reported in the reduction of Methylene blue by $\mathrm{NaBH}_{4}$ and Reduction of benzyl chloride (Suvith and Philip 2014 and Jebakumar Immanuel Edison and Sethuraman 2013).

Due to increasing population and urbanization the environment has been damaged to a greater extent and an immediate and permanent action is needed. The advent of nanoremediation, using smarter technologies remains as a boon for the environment. Ample possibilities remain in the exploitation of green synthesis tactics based on biogenic approach. The nanobased technologies remains eco-friendly, cost effective and less 
time consuming. The results obtained from the sensors activated by means of nano materials are reliable. This promising and innovative technology helps us to understand the uses of nanoparticles in both basic and field demonstrations.

Fig.1Various forms of nanoparticles

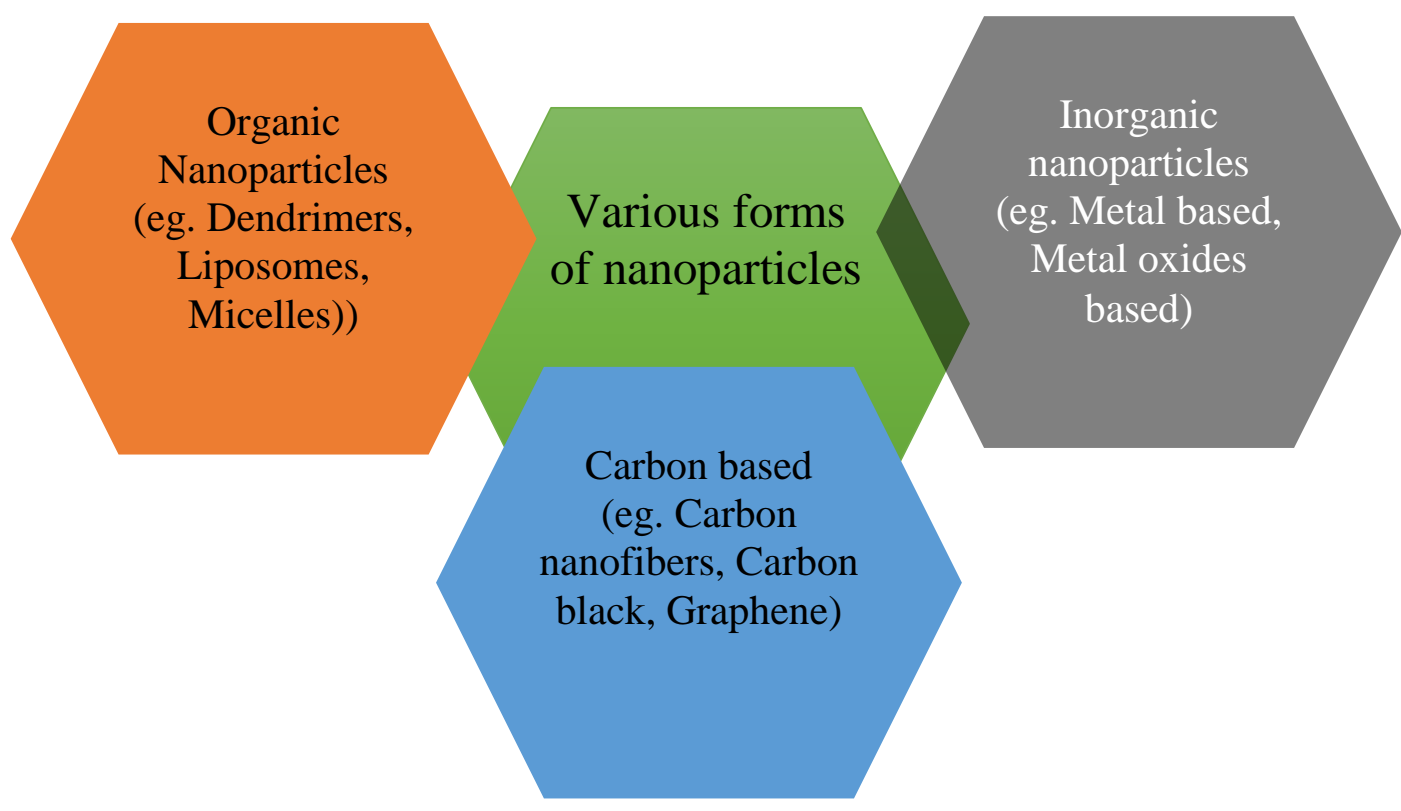

\section{References}

Abhilash M (2010) Potential applications of Nanoparticles. Int J Pharma Bio Sci 1:

Akbarzadeh A, Sadabady RR-, Davaran S, (2013) Liposome: classification, preparation, and Applications. Nanoscale Res Lett, 8:102.

Asad M, Sheikhi MH (2016) Highly sensitive wireless $\mathrm{H} 2 \mathrm{~S}$ gas sensors at room temperature based on CuO-SWCNT hybrid nanomaterials, Sensor. Actuat B-Chem 231:474_483.

Balavigneswaran CK, Kumar TSJ, Packiaraj RM, Prakash S (2014) "Rapid detection of $\mathrm{Cr}(\mathrm{VI})$ by $\mathrm{AgNPs}$ probe produced by Anacardium occidentale fresh leaf extracts,." Appl Nanosci 4:367-378,

Butnar I, Llop M Composition of greenhouse gas emissions in Spain: an input-output analysis,. Ecol Econ 61:388-395.

Choi H, Zakersalehi A, Al-Abed S (2014) nanostructured titanium oxide filmand membranebased photocatalysis for water treatment. In: Savage ASSD (ed) Nanotechnology applications for clean water, 2nd edn. William Andrew Publishing, Oxford,. pp 123-132.

Chong M, Chow C, Saint C (2010) Recent developments in photocatalytic water treatment technology: a review. Water Res 44:2997-3027.

Collier C, Vossmeyer T, Heath J (1998) Nanocrystal superlattices. Ann Rev Phys Chem 49:371-404.

Comini E (2006) Metal oxide nano-crystals for gas sensing. Anal Chim Acta 568:28-40.

Dahoumane S, Yéprémian C, Djédiat C (2016) 
Improvement of kinetics, yield, and colloidal stability of biogenic gold nanoparticles using living cells of Euglena gracilis microalga. $\mathbf{J}$ Nanoparticle Res https ://doi. org/10.1007/s1105 1-016-3378-1.

Doble M, Kruthiventi A (2007) Green chemistry and engineering. Cambridge Acad Press

El-Rafie H， El-Rafie M, Zahran M (2013) Green synthesis of silver nanoparticles using polysaccharides extracted from marine macro algae. Carbohydr Polym 96:403-10.

Garg A, Sharad V, Pramod Kumar S, Kumar N (2011) Formulation, characterization and application on nanoparticle: a review. Der Pharm Sin 2:17-26.

Gericke M, Pinches A (2006) Microbial production of gold nanoparticles. Gold Bull 39:22-8.

Han, Liu B, Xing X, (2016) A high response butanol gas sensor based on $\mathrm{ZnO}$ hollow spheres. Sens Actuat B-Chem 237:423-430

Hristozov D, Ertel J (2009) Nanotechnology and sustainability: benefits and risks of nanotechnology for environmental sustainability,. Forum der Forsch 22:161-168.

Husen A, Siddiqi K (2014) Plants and microbes assisted selenium nanoparticles:characterization and application.. J Nanobiotechnol 12:28

Hutchison JE (2008) Greener nanoscience: a proactive approach to advancing applications and reducing implications of nanotechnology,. ACS Nano 2:395_402.

Jadhav SD, Jadhav MS, Jawale RW (2013) Study of chloride and nitrate concentration of MulaMutha River in Pune city (Maharashtra). Int J Chem Life Sci 2:1140-1142.

Jebakumar Immanuel Edison TN, Sethuraman MG (2013) "Electrocatalytic reduction of benzyl chloride by green synthesized silver nanoparticles using pod extract of Acacia nilotica,." ACS Sustain Chem Eng 1:1326-1332

Jovin T (2003) Quantum dots finally come of age. Nat Biotechnol 21:32-33

Khan M, Al-Marri A, Khan M (2015) Green approach for the effective reduction of graphene oxide using Salvadora persica L. root (Miswak) extract. Nanoscale Res Lett 10:1-9.

Kumar O, Al-Dossary G, Kumar A, Umar (2015) Zinc oxide nanostructures for $\mathrm{NO} 2$ gas-sensor applications: a review,. Nano-Micro Lett 7:97-120.

Kurniawan T, Sillanpää M (2011) Nanoadsorbents for remediation of aquatic environment: local and practical solutions for global water pollution problems. Crit Rev Env Sci Technol 42:1233-1295

Ladj R, Bitar A, Eissa M (2013) Individual inorganic nanoparticles: preparation, functionalization and in vitro biomedical diagnostic applications. J Mater Chem B, 1:1381 1396.

Löffler FE, Edwards EA (2006) Harnessing microbial activities for environmental cleanup. Curr Opin Biotechnol, 17:274-284.

Mohanpuria P, Rana N, Yadav S (2008) Biosynthesis of nanoparticles: technological concepts and future applications. J Nanoparticle Res 10:507-17

Murugan A, Kumara K, Shanmugasundaram (2014) Biosynthesis and characterization of silver nanoparticles using the aqueous extract of vitex negundo. linn. World J Pharm pharm Sci 3:1385 1393 .

Narayanan K, Sakthivel N (2011) Synthesis and characterization of nanogold composite using Cylindrocladium floridanum and its heterogeneous catalysis in the degradation of 4- 
nitrophenol. J Hazard Mater 189:51925.

Ozgur YI, Alivov C, Liu A (2005) A comprehensive review of $\mathrm{ZnO}$ materials and devices,. J Appl Phys 98:1-103.

Prasad Rao J, Kurt Geckeler E (2011) Polymer nanoparticles: Preparation techniques and size-control parameters. Prog Polym Sci 36:887-913.

Rajan S (2011) Nanotechnology in groundwater remediation. Int J Env Sci Dev 2:182-187.

Sun Q, Cai X, Li J (2014) Green synthesis of silver nanoparticles using tea leaf extract and evaluation of their stability and antibacterial activity. Colloids Surf A Physicochem Eng Asp 444:226-31.

Suvith VS, Philip D (2014) "Catalytic degradation of methylene blue using biosynthesized gold and silver nanoparticles,." Spectrochim Acta Part A Mol Biomol Spectrosc 118:526-532

Thakkar K, Mhatre S, Parikh R (2010)
Biological synthesis of metallic nanoparticles. Nanomed Nanotechnol Biol Med 6:257-62

Wang HL, Dai HJ (2013) Strongly coupled inorganic-nano-carbon hybrid materials for energy storage,. Chem Soc Rev 42:3088_3113.

Wang W, Chen DH, Xu BS (2009) Simple, rapid, sensitive, and versatile SWNTpaper sensor for environmental toxin detection competitive with ELISA. Nano Lett 9:4147-4152.

Whatmore R (2006) Nanotechnology what is it? Should we be worried? Occup Med 56:295-299.

Zhang J, Liu XH, Neri G, Pinna N (2016) Nanostructured materials for room temperature gas sensors. Adv Mater 28:795-831.

Zhang X, Jia XJ, Lv YL (2010) Fluorescent quantum dotlabeled aptamer bioprobes specifically targeting mouse liver cancer cells,. Talanta 81:505_509.

\section{How to cite this article:}

Saritha, S. and Prabha, V. 2019. Green Synthesis of Nanoparticles and their Possible Avenues in Environmental Application - A Review. Int.J.Curr.Microbiol.App.Sci. 8(10): 2644-2650. doi: https://doi.org/10.20546/ijcmas.2019.810.305 